\title{
Nigeria and bamboo plants as a forest product
}

\author{
Okwori, Robert Ogbanje Phd ${ }^{1}$ Chado, Mohammed Diko Ph.d ${ }^{2}$ \\ ${ }^{I}$ Department of Industrial and Technology Education, Wood Technology Section, FederalUniversity of \\ Technology, Minna, Niger State, Nigeria, \\ ${ }^{2}$ School of Technical Education, Niger State College of Education, Minna Niger State, Nigeria.
}

\begin{abstract}
Bamboo is one of the most valuable non-timber products in the world today and it provides livelihood to millions of people in the world. The paper explained bamboo and discussed the morphology of a bamboo plant. It explained the uses and properties of bamboo. The paper also identified impediments to effective utilization of bamboo as a forest product in Nigeria. Some of these impediments include lack of public awareness in the use of bamboo for modern construction work, lack of bamboo research institute, unavailability of technical experts for processing bamboo and government attitude towards bamboo as a forest product. The paper suggests establishment of Bamboo research institute for conducting researches in bamboo and for the production of technical personnel for processing bamboo.
\end{abstract}

Key words: Bamboo, Morphology, Properties, Structure, Wood industries

\section{Introduction}

Bamboo is a giant woody grass that grows in tropical and subtropical regions in the world. Bamboo has a fast growth rate of four to six years of planting. It can grow up to four feet in a day. Reference [1] explained that bamboo stalk can be cut leaving the roots intact to grow. Each plant can stay up to 75 years and bamboo reaches harvesting maturity in three to six years. Bamboo can be managed on land that is unsuitable for agricultural crops. Markets for bamboo are growing rapidly as many countries have insufficient capacity for wood production and Bamboo is very versatile and effective substitute for wood as presented in [2].Itwas revealed in [2] that Based on the available United Nations data, the global export value of bamboo commodities increased to US\$ 4.3 billion in 2005, from US $\$ 2.8$ billion in 1995, with furniture export growing steadily from US $\$ 1.3$ billion to US $\$ 2.4$ billion. Bamboo is mostly produced by Asia countries and china is the largest bamboo producer. The countries that are mostly involved in export of bamboo products are: China $57.3 \%$, Indonesia $14.8 \%$, Vietnam 4.6\%, European Union 3.0\%, U.S.A 1.7\%, Philippines 1.6\%, Thailand 1.0\%, Singapore 1.0\%, Myanmar $0.8 \%$ and Malaysia $0.8 \%$ as revealed in [3]. It is clearly seen that Nigeria is not among the countries exporting bamboo while is among the International Network for Bamboo and Rattan. Countries that are among International Network for Bamboo and Rattan are as follows: Africa: Republic of Benin, Cameroon, Ethiopia, Ghana, Kenya, Madagascar, Mozambique, Nigeria, Rwanda, Sierra Leone, Tanzania, Togo and Uganda. Asia: Bangladesh, Bhutan, China, India, Indonesia, Malaysia, Myanmar, Nepal, the Philippines, Sri Lanka and Vietnam. America: Argentina, Canada, Chile, Colombia. Cuba, Ecuador, Peru, Suriname. Oceania: Tonga. This was disclosed in [3].

It is disgusting to say that Nigeria is not one of the exporters of bamboo products after registering as a member of International Network for Bamboo and Rattan. Bamboo has over 1250 species that grow through out the world. More than 100 of these species are used commercially [4].Some of the species include dedendrocalamous giganteous, oxyenanthera braunii, phyllostachys nigra . Out of this 1250 species , there is no one planted at large quantity for commercial purpose in Nigeria. It is only at the substance level.

Forest is a land with trees, bamboos and shrubs. The forests that are commonly found in many countries are tropical, temperate and boreal. The tropical forests are ecologically rich forest and they regenerate easily. The temperate forest are mostly found in areas such as North America, North Eastern Asia, west and central Europe while boreal forests or taiga forests are found in areas with shorter, warm summers and winters. Regeration is slow in these types of forest [5]. In reference [6], Beak Consultants classified forest types in Nigeria into eight. These forests are savanna and woodland, lowland and rain forest, fresh water swamps forest, mangrove forest, montane forest, riparian forest, plantation (agriculture) and plantation (forest). These forests are found in the east, south and western part of the country including some parts of the middle belt of Nigeria. The forests classified by Beak consultant were not from the arid states in the Northern part of Nigeria. These states include Sokoto, Zamfara, Katsina, Jigawa, Yobe, Borno, Gombe and Bauchi.

\subsection{The Morphology of a Bamboo Plant}

The morphology of the bamboo plant is concerned with the outer appearance of the plant which includes the following parts as presented in [4]. 
a. Node: It is the joint or circular ridged on the bamboo stalk or Culm. The node is a narrow band of hard plant fiber that penetrates through the entire diameter of the culm. In the majority of bamboo species, the stalks or culms in the internode region are hollow.

b. Sheath: The new nodes and elongating internodes regions are usually first wrapped by a culm of leaf sheath. As the culm thickens, the sheath begins to tear away from the culm at its base, leaving the distinctive ring at the node.

c.. Sulcus: In some species of bamboo, in the internode region, there is a vertical groove called the Sulcus in the internode region. This groove is caused by the presence of a branch bud that is emerging from the node.

d. Branches: Buds may emerge from the node and elongate, forming branches. An additional bud called the branch can grow creating a pair or $\mathrm{V}$ - like branches from the node. Branches can be many depending on bamboo species .

e. Culm: The Culm refers to the stem or trunk. It is the most distinguished feature of a bamboo plant. It varies in size, shape and colour. The appearance can range from thick, thin, short, erect or bent. Most culms are round in shape. Most of the Culms colour is green except garden bamboo that are black (Phyllostachys nigra) and the culms exhibit nearly jet black colour. New culms mostly emerge in the spring time. However, it varies among species.

f. Leaves: leaves are present at the main portion of the bamboo plant which includes the rhizomes, culm and branches. Leaves serve as protective covers that encase the rhizome as it travels under the soil. The leave provides photosynthetic function of the plant by converting sunlight into energy. The appearance of the leave varies among species. In some species, the leaves are very large and less numerous while other species have large amount of very small leaves. The appearance of leaves plays a vital role in its identification.

g. Roots: The root anchors the Culm to the soil. It takes mineral from the soil and passes it through the Culm to other parts of the bamboo. Roots allow the Culm to grow and have weight because of the mineral taken from the soil through the roots. The root of the bamboo does not penetrate beyond $300 \mathrm{~mm}$ below the surface of the soil. They vary in sizes and shapes. This depends on the species. The root structure of the bamboo also serves as a bio - filter for water run off [7]. Fig. 1 and 2 show the morphology of a bamboo plant and bamboos

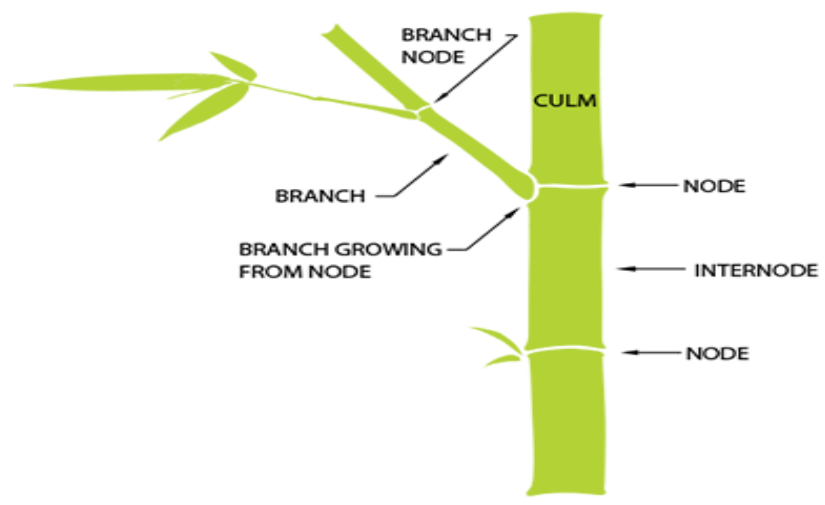

Figure.1 The morphology of a bamboo plant Source: $\underline{w w w . b a m b o o b o t a n i c a l s . c a / h t m l}$.

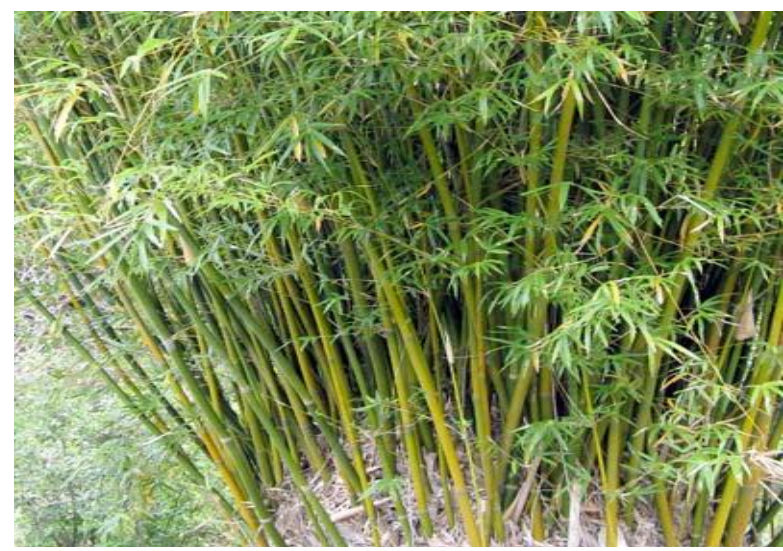

Source: www.botanicals.ca/html

Figure. 2. Bamboos 


\section{Properties of Bamboo}

Bamboo possesses some properties which makes it suitable for constructional work. The properties of bamboo are discussed below.

a. Chemical Property: The main constituents of bamboo culms are cellulose and lignin. Higher benzene-ethanol extractives of some bamboo species is an advantage for decay resistance [8]. The ash content of bamboo is made up of inorganic minerals primarily silica, calcium, potassium, manganese and magnesium. Silica content is higher in the epidermis with very little in the nodes and is absent in the internodes. Higher ash content in some bamboo affects the processing machinery[8]. Reference [8] stated that the carbohydrate contained in bamboo plays vital role in the durability of the bamboo.

b. Physical and Mechanical Properties: The physical and mechanical properties of bamboo vary with the age of the bamboo and the height of the Culm [8]. According to reference [9], the increase in weight of the culm depends age of the bamboo. The density of bamboo culm is as a result of the distribution of fiber around the vascular bundle of the culm. Though, the light weight of bamboo makes it to perform better in shear stress than materials of greater mass as noted by [10].

\section{The Uses of Bamboo}

Building Materials: Bamboo is an indispensable material for construction besides its traditional applications. Bamboo is used for structural members such as trusses, kingpost and purlin in modern buildings etc. Bamboos don't break easily and its original shape is regained when the load subjected to it is removed. It is good for reinforcing concrete [10].

Bamboo Based Panel : China started producing bamboo panels in the early $19^{\text {th }}$ century. At present more than twenty different types of panel are produced in Asia. Bamboo fiber is longer than wood fiber which gives bamboo some technological advantage. It is used for flooring, veneer, strip boards, mat boards, fiber boards, particle boards, medium density boards and so on [11]. Some modern buildings are completely made of bamboo in Asia which can not be differentiated from wood in terms strength and durability.

Furniture: Bamboo is used for different kinds of furniture in Asia especially China. It is used for producing beds, cupboard, table, upholstery chairs. Laminated bamboo furniture is growing rapidly in the world especially Asia. When bamboo is laminated and used to produce furniture, it is difficult to differentiate it from wood.

Paper and Pulp: Countries such as China and India use bamboo for producing pulp and paper. Paper made from bamboo has the same quality with paper made from wood. Its brightness and optical properties remain stable while those paper make from wood may deteriorate over time. The morphological characteristics of bamboo fibers give paper made from bamboo a high tear index as disclosed in [11 \&12].

Charcoal: I was observed in [11] that bamboo is used for charcoal as a substitute for wood charcoal or mineral coal and activated bamboo charcoal can be used for cleaning the environment, absorbing excess moisture.

Utensils: Bamboo is used for producing utensils such as spoons, plates, cup and serving tray. It is also used for producing tooth pick.. The fiber of bamboo can be used for producing yarn and fabric. The shoots of bamboo also serve as food for some people in Asia. Bamboo is extensively used in some parts of the world.

\section{Impediments to Effective Utilization of Bamboo in Wood Industries in Nigeria}

Reference [11] pointed out that bamboo is the second China's forest products. Bamboo plants grow quickly and have the ability to propagate easily. It has been observed that Asia countries and some developed countries make use of bamboo very well which contributes to the economic development of their countries while opposite is the case with Nigeria. The paper therefore, identifies impediments to effective utilization of bamboo in wood industries in Nigeria. These impediments include lack of public awareness in the use of bamboo in modern buildings and furniture, lack of bamboo research institute, unavailability of technical experts for processing bamboo for use, lack of facilities for processing bamboo for domestic and industrial work and government attitude towards the use of bamboo in Nigeria.

a. Lack of Public Awareness in the use of Bamboo in Modern Buildings and Furniture. It is not an over statement to stay that many carpenters and cabinet makers in Nigeria do not know that bamboo is used for roof structural members such as kingpost, purlin, rafters, tie beam in modern buildings and also furniture of different kinds after processing and laminating it. Most woodworkers are only acquainted with the traditional method of using bamboo in buildings and furniture. In China, some buildings are completely made of bamboo except the roof. This includes the wall and roofing members. It is also used for wall paneling, doors, windows and so on. It has also boasted the economy of China to the extent that they are the highest exporter of bamboo products.

b. Lack of Bamboo Research Institute: It is obvious that the main factor that prevents effective use of bamboo in wood industries in Nigeria is lack of bamboo research institute. If there is a bamboo research institute 
like China, India and other countries, bamboo will be effectively utilized in Nigeria which will reduce over dependence on wood. These deforestations in parts of the country due to over reliance on solid timber will be reduced. Bamboo research institute promotes the use of bamboo by carrying out researches relating to bamboo and also for training technical and nontechnical staff in the area of bamboo. When bamboo is properly used trees will be preserved for the conservation of biodiversity, protect soil and fight climate change.

c. Unavailability of Technical Experts for Processing Bamboo. It is a fact that due to lack of bamboo research institute in Nigeria and nonchalant attitude of government towards the use of bamboo, the technical experts for processing bamboo for use in modern buildings and furniture are lacking. Most sawmills and wood industries in Nigeria do not have the technical staff for processing bamboo.

d. Lack of Facilities for Processing Bamboo for use. In Asia and other countries that bamboo is greatly used for construction work, the required facilities for processing it are available. In Nigeria, most sawmills and wood industries do not have facilities for processing bamboo because they are not using it for furniture and other construction work. Even, wood technology students who are interested in carrying out researches on bamboo hardly have access to facilities for their studies.

e. Government Attitude Towards Bamboo as a Forest Product. The government seems to have nonchalant attitude towards bamboo as a forest product when compared to wood while some countries like China rely much on bamboo which has boasted their economy very well due to revenue generated yearly from it. It was revealed that Nigeria is a member of International Network for Bamboo and Rattan but has never exported bamboo nor use it effectively. The reason why Nigeria is not among the countries exporting bamboo is because of government's nonchalant attitude towards bamboo as a forest product. It is not surprising because Nigeria has no bamboo research institute and there is no bamboo plantation. It is also good to embrace bamboo instead of relying completely on wood. When bamboo is embraced it will serve as substitute for wood since wood is used for everything in Nigeria. For instance, building construction, furniture, charcoal and so on and it will boast the country economically just as China.

\section{Conclusion}

Bamboo is one of the forest products in Nigeria but practiced at substance level. Nigeria is not one of the exporters of bamboo due to non-challant attitude of government towards bamboo as a forest product. If Nigeria embraces the use of bamboo for furniture and other construction work, they will think of having bamboo plantation in every state and this will boast the economy of the country by selling it to individuals, construction companies and also exporting them to other western countries. It will also aid in preserving trees for the conservation of biodiversity and fight climate change.

It is suggested in the paper that Bamboo research institute should be established in Nigeria. This will enhance researches on bamboo and boast effective use of it. Forestry departments in Nigerian universities, federal and State Ministries of Agriculture (Forestry Section) should create awareness by using mass media, radio and television on the relevance of bamboo to the society. Workshops and conferences should be organized by forestry departments of Nigeria Universities and experts be invited to educate government and public on the use of bamboo for producing modern furniture and other construction work. Bamboo plantation should be established in every local government of Nigeria for protection of the soil.

\section{References}

[1] "Bamboo Morphology,Structure and Anatomy". Available online at http://www.complete bamboo.com/bamboo-species.html. Retrieved on the April $2^{\text {nd }}, 2013$.

[2] International Network for Bamboo and Rattan (INBAR), "Partnership for Better World". Beijing China: International Bamboo and Rattan, 2004,.6.

[3] International Network for Bamboo and Rattan, "Partnership for Better World". Beijing China: International Bamboo and Rattan, 2011,20 .

[4] "Bamboo Structure". Available online at http:www.ehowcompfacts-5821966-structure-bamboo-stacks.html. Retrieved on the April27th, 2013.

[5] Food and Agricultural Organization (FOA)," Different types of forest." Available online file://c/Documents and forest-1 what is a forets.html. Retrieved on May $20^{\text {th }} 2013$

[6] Beak Consultants,"Forest reserve situation" Available online at www.for.org/docrep/004/ab578e04.htm assessment in Nigeria. Retrieved on May $31^{\text {st }}, 2013$.

[7] "Bamboo Anatomy". Available online at wwwbamboobotanicals.ca/html. Retrieved on the may $1{ }^{\text {th }}, 2013$.

[8] X, Li,." Physical, Chemical and Mechanical Properties of Bamboo and its Utilization Potential for Fiber Board Manufacturing," Available online at etd.isu.edu/docs/available/etd-04022004-144548/unrestricted/li-thesis.pdf. Retrieved on the May $20^{\text {th }}, 2013$.

[9] P.Shanwughavel, P.S. Peddappaiah and W. Liese,,".Recent Advances in Bamboo Research". Available online: http://www.vedamsbooks.com. Retrieved on the May3rd, 2013.

[10] "Bamboo Structure: A Quick Growing Alternative to Building with 2 X4S". Available online at http://www.weyerhaecuser.com/aboutus/facts/7.4Harvest Regenaration.pdf.retrieved on the April $2^{\text {nd }}, 2013$.

[11] S. Jamatia, "Livelihood of the Bamboo Base: Challenges and Opportunities," Proceedings of 54th Society of Wood Science and Technology conference on sustainable development of wood and biomass in our new global economy, Beijing China: International Bamboo and Rattan, 2012, 20. 
[12] L. Zing-Ming and L. Cheng, "Preparing and Morphology of nanocrystalline from Cellulose from Bamboo Pulp," Proceedings of $54^{\text {th }}$ Society of Wood Science and Technology conference on sustainable development of wood and biomass in our new global economy, Beijing China: International Bamboo and Rattan,2012, 72.

[13] L. Ham, L. Zhang, L. Li and Q. Yong, " Bio-refining of Bamboo Residues. Proceedings of 54th Society of Wood Science and Technology conference on sustainable development of wood and biomass in our new global economy, Beijing China: International Bamboo and Rattan,2012, 27. 